\title{
Juggling Selves: Navigating Pre-service Teaching Experiences in Overseas Contexts
}

Educating the Global Citizen LMU Munich 25-28 March 2019

Dr Michiko Weinmann Deakin University michiko.weinmann@deakin.edu.au @MichikoWeinmann

Dr Rod Neilsen Deakin University rod.neilsen@deakin.edu.au

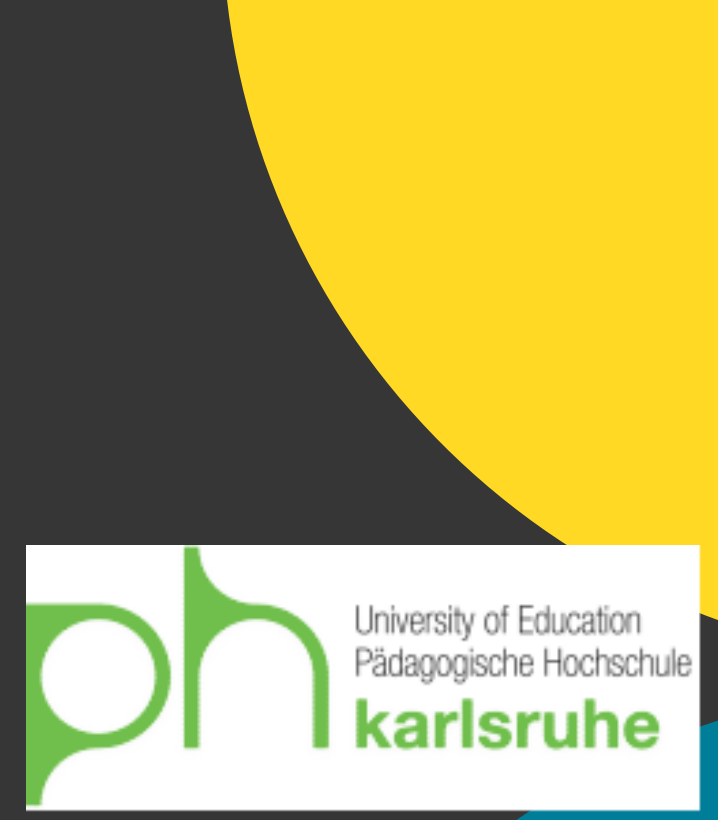

Prof Dr Isabel Martin PH Karlsruhe martin01@ph-karlsruhe.de 


\section{Setting the scene}

I love adventure and walking around the streets. Like learning different flavours, like talking to different people. I walked to the park and the circus is there, and we joined them tight-roping. Little experiences like that that you just wouldn't get anywhere-not in the suburbs in Melbourne. They don't know English and you don't know Spanish, but you somehow conjure up a conversation; they were teaching us juggling and we didn't know [Spanish]-you just learn [in] different ways.

(Lachlan, pre-service teacher, participant in the Chile Global Education Program)

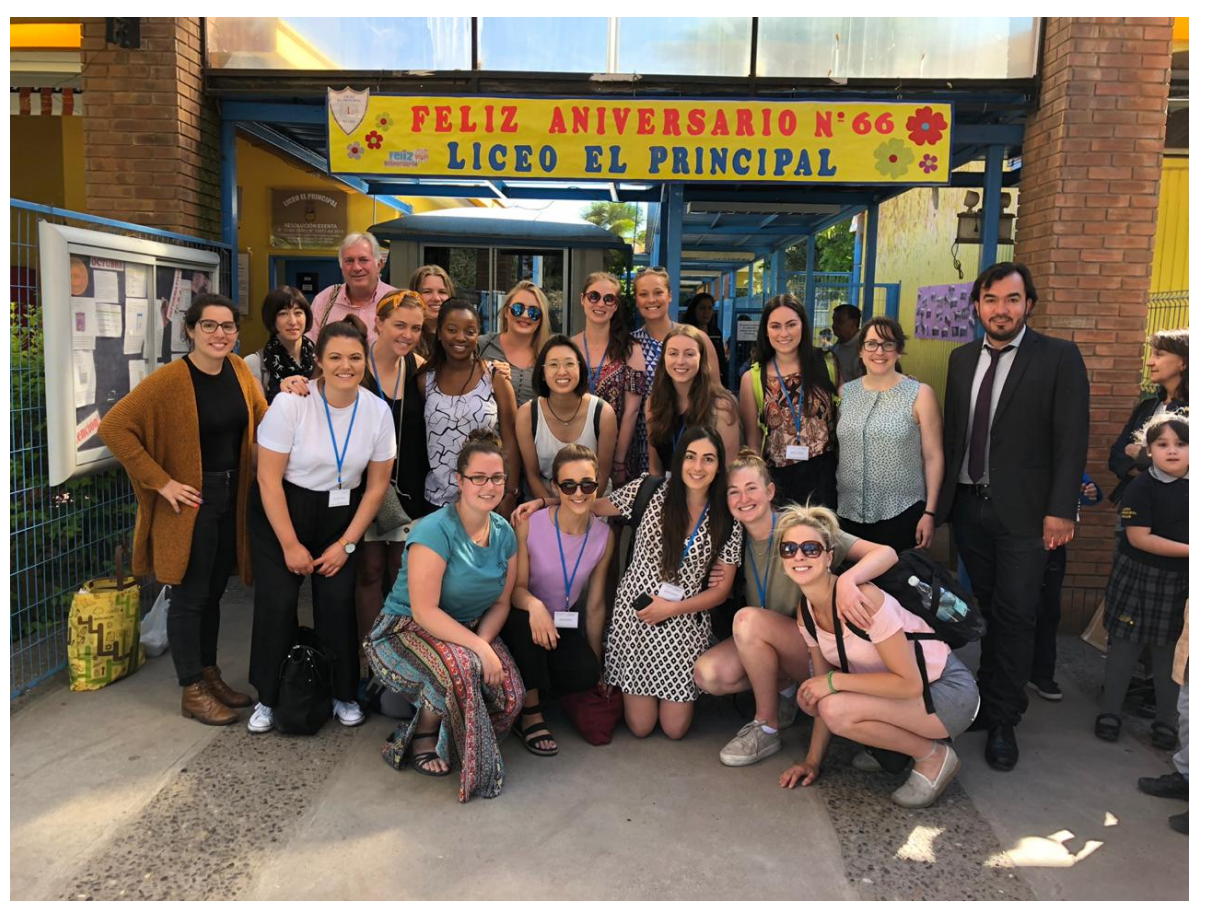




\section{Mobility in Teacher Education}

- Global mobility programs for pre-service teachers are an increasingly integral component of many teacher education courses.

- $\quad$ Such programs are perceived as important opportunities for pre-service teachers to engage with diversity and to develop skills to respond to increasingly multicultural and multilingual classrooms.

- $\quad$ Much research has shown the effects of mobility programs on transnational competencies, and has investigated the impact of international field experiences on (pre-service) teachers' identities (Block 2007; Ellwood 2011; Kinginger 2013; Porsch and Lüling 2017). 


\section{Mobility in Teacher Education cont.}

- Research into international teaching practicums has shown that student teachers develop intercultural awareness, inclusive teaching practices and flexibility,

- BUT: global mobility programs can also reinforce cultural stereotypes, neo-colonial attitudes and a sense of superiority and entitlement.

- Our study explores the ways in which students articulated intercultural professional encounters, to gain a better understanding of how renegotiation of self and other may or may not take place, and of the underpinning ideologies that shape such encounters. 


\section{The programs}

Our comparative study draws on two mobility programs for preservice teachers: an Australian program in Santiago, Chile (Deakin University), and a German program in Laos (PH Karlsruhe).

The Australian program:

- Established in 2017, in cooperation with a university in Santiago

- 'Global Education Program' (duration of 3 weeks, i.e. 15 school placement days; for Bachelor of Primary Education students and BA/BTeach students)

- Around half the Australian group was also enrolled in an elective course unit designed with GEPs in mind: 'Teaching in a Global World'.

- No previous Spanish language study

- Students usually do not have a specialisation in EAL/D (English as an Additional Language (or Dialect) pedagogy 


\section{The programs cont.}

The German program:

- 'The Laos Experience: Bi-directional learning and teaching' was established in 2015 by Karlsruhe University of Education (Pädagogische Hochschule Karlsruhe and the German foundation Angels for Children.

- Program runs twice yearly, for two months.

- Bi-directional program in which German students and graduates work in tandem with Lao teacher-partners, with the aim of supporting and improving teacher education in Laos, especially in English, Physics, Chemistry, Biology and Mathematics.

- No common language at the outset, as English language proficiency is generally low (A1-A2), or non-existent, among the Lao teachers. Communication initially takes place through gesture, lesson modelling-even via Google Translate. 


\section{Methodology: Sense-Making}

- A process that 'emerges from efforts to create order and make retrospective sense of what occurs' (Weick 1993: 635)

- A mechanism to explore and better understand how (preservice) teachers make sense of their profession, social and political school contexts, and of the various factors that contribute to their becoming teachers.

- Kelchtermans (2009) Personal Interpretive Framework (PIF) analysis tool attempts to capture how teachers interpret the complexity of their role and how they position themselves. 


\section{Constructs (PIF)}

Making sense of the unfamiliar: environmental, cultural and language-related aspects, school and classroom contexts, interactions with local students and teachers.

Making sense of the overall experience: end-of-program reflections on 'take home' elements of the program, which include professional and (inter)cultural and personal aspects; reflections from a returning-home perspective.

Making sense of self: reflections on how and in what ways the program was able to transform pre-service teachers' sense of identity. 


\section{Theoretical underpinnings}

Global mobility programs are embedded within discourses of postcolonialism (Rizvi, Lingard \& Lavia, 2006).

The necessity of interrogating and shifting the binaries is still present in postcolonial perspectives; such re-theorisation is key in resuming the tasks of the intellectual and subjective task of decolonisation (Chen, 2010).

Transnational, transcultural pedagogical programs create a powerful space for neo-colonial preconceptions to be set against moments of discovery unveiling the limitations of established parameters that define our sense of self within 'imagined communities' (Anderson, 1991).

When teachers 'are adequately prepared to examine their worlds critically, they are in a better position to advocate for their students and to teach their students to advocate for themselves' (Motha, 2014). 


\section{Method: Participants, methods and data analysis}

- Qualitative, small-scale case studies.

- $\quad$ Fifteen third-year Australian pre-service teachers in their early twenties from Deakin University, participating in the Santiago GEP.

- Three focus groups of approximately one hour were held in the final week of the program with the two accompanying academic coordinators.

- $\quad$ For the Laos program, data were collected through individual interviews across two groups: returnees (7) and outgoing participants (10).

- Data from 43 written final reports since 2015 and previous weekly reports describing program and tandem experiences were also selected for analysis.

- The participants were of different ages (20-28 years old) and at different stages of study. 


\section{Making sense of the unfamiliar}

...so opposite, very culturally distant, the food, the people, the coffee ... nobody could imagine a family sitting outside of the house cooking on an open fire (Verena, Laos).

Yeah, everyone's really nice, and sometimes it's maybe a little bit too over the top nice, compared to what we're used to. (Leah, Chile) 


\section{Making sense of the unfamiliar cont.}

They don't have any floor space, and there's a lot of them packed into one small room. So we're very fortunate in Australia to have such flexible learning spaces, whereas here-they've got their little desk and that's kind of it (Maddy, Chile).

The classrooms are quite noisy here, and they [the students] talk so much, I feel they could benefit so much from incorporating maybe some collaborative learning in with that talk (Leah, Chile). 


\section{Making sense of the overall experience}

I guess the one thing that I'm going to take away from this is try and teach [to] the best of your ability, even when it's [a] culture that isn't your own. You can always find a way, I suppose, to reach out and teach them a bit about the world, a bit about themselves, and they can put the pieces together (Chris, Chile).

Now I see the learners' progress and it makes me happy, to see that you can really do something by your own teaching...I can't believe to have been part of such a meaningful project [that means] doing something in the world (Verena, Laos). 


\section{Making sense of self}

I got to know some negative characteristics of my own. I judged [tandem-partner] in the beginning (quiet, poor English), in the end she was my friend, still texts me about her lessons sometimes (Silvia, Laos).

There was always a cultural distance but I tried to be open or sometimes adapt-it's very difficult to talk about it; there are two of me. (Verena, Laos) 


\section{Outlook}

I love adventure and walking around the streets. Like learning different flavours, like talking to different people. I walked to the park and the circus is there, and we joined them tight-roping. Little experiences like that that you just wouldn't get anywhere-not in the suburbs in Melbourne. They don't know English and you don't know Spanish, but you somehow conjure up a conversation; they were teaching us juggling and we didn't know [Spanish]you just learn [in] different ways.

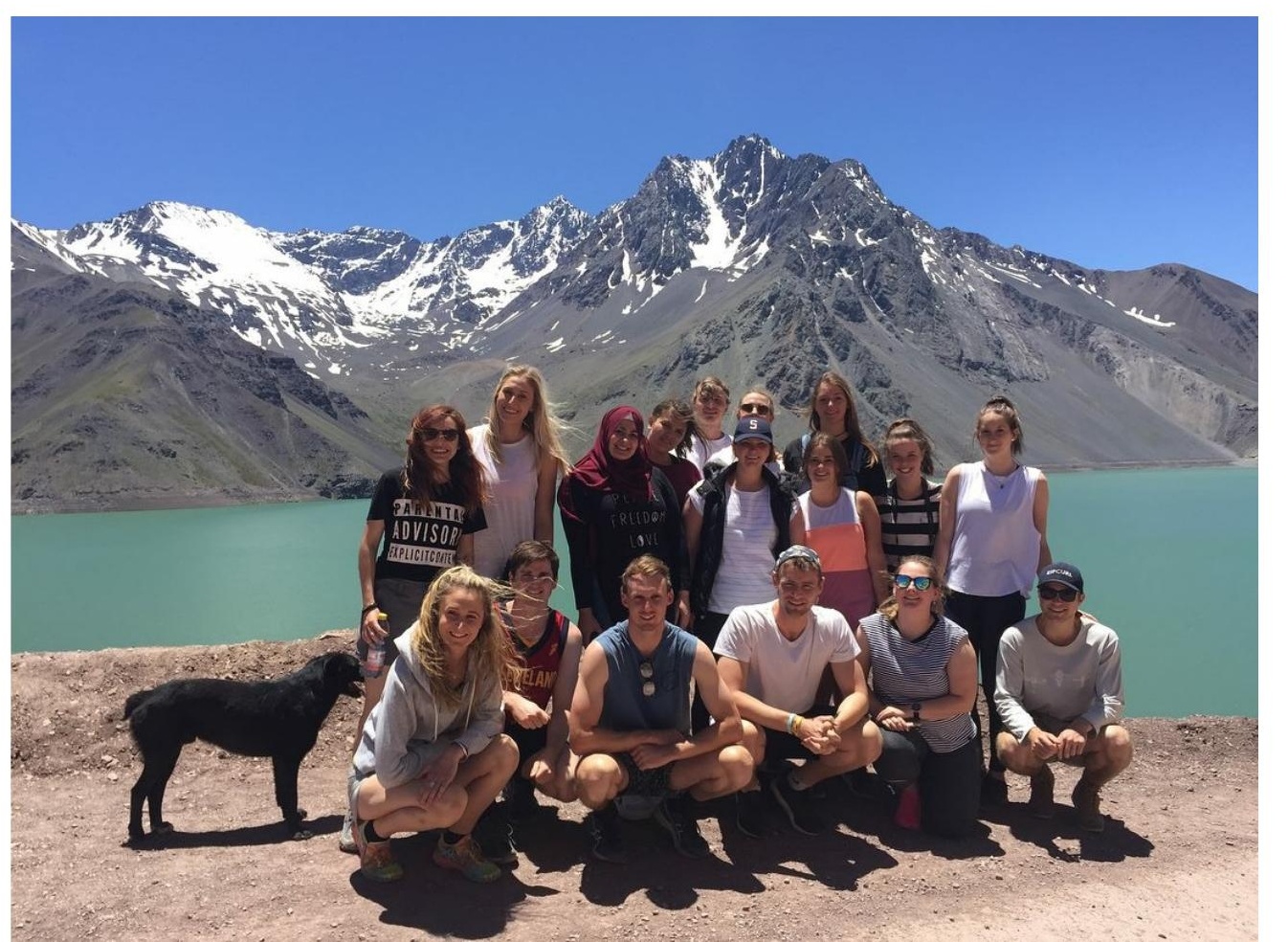




\section{Concluding thoughts}

- Developing teacher expertise that is well placed to respond to the diversity of globalised classrooms involves complex engagement and reconfiguration of identity, pedagogy and practice in contexts shaped by different economic, social, and political relations.

- This has implications for the design of global mobility programs and the role of supporting courses, units, seminars and academic coordinators, whose role implies bridging the gap between 'the familiar' and 'the unfamiliar'

- Reimaginations of geographical and cultural conceptions within global mobility programs need to question our responsibilities as members of new 'places'.

- Such questions have been asked before, but as these programs are situated within continually re-forming discourses of globalisation, they may therefore require new answers. 


\section{References}

Anderson, B. (1991). Imagined communities: reflections on the origin and spread of nationalism. London: Verso.

Block, D. (2007). Second Language Identities. London: Continuum.

Chen, K.H. (2010). Asia as method: Towards deimperialisation. Durham: Duke University Press. Ellwood, C. (2011). "Undoing the Knots: Identity Transformations in a Study Abroad Programme." Educational Philosophy and Theory 43, no. 9: 960-78.

Kinginger, C. (2010). American students abroad: Negotiation of difference? Language Teaching, 44, 216-227.

Kelchtermans, G. (2009). Who I am in how I teach is the message: Self-understanding, vulnerability and reflection. Teachers and Teaching, 15, 257-272.

Motha, S. (2014). Race, empire and English language teaching: Creating responsible and ethical antiracist practice. New York: Teachers College Press.

Porsch, R., and Lüling, S. (2017). "Reentry-Erfahrungen durch Lehramtsstudierende mit einer modernen Fremdsprache nach einem Auslandsaufenthalt." Zeitschrift für Fremdsprachenforschung 28, no. 3: 259-83.

Rizvi, F., Lingard, B., \& Lavia, J. (2006). Postcolonialism and education: negotiating a contested terrain. Pedagogy, Culture \& Society, 14(3), 249-262.

Weick, K. (1993). The collapse of sensemaking in organizations: The Mann Gulch disaster. Administrative Science Quarterly, 3: 628-652. 


\section{Thank you!}

Weinmann, M., Neilsen, R. \& Martin, I. 'Juggling Selves. Navigating Preservice Teaching Experiences in Overseas Contexts'. (forthcoming 2019). Chapter accepted for publication in German Transnational Education and Comparative Education Systems: An Update on Research and Practice, Springer. https://www.springer.com/series/15756

The Laos Project http://www.thelaosexperience.com/ 